\title{
Warm Stratification and Chemical Treatments Overcome the Dormancy and Promotes Germination of Colchicum kotschyi Boiss Seeds under in Vitro Condition
}

\author{
Morteza ALIREZAIE NOGHONDAR ${ }^{1}$, Hossein AROUEE', Shamsali REZAZADEH ${ }^{2}$, \\ Mahmoud SHOOR', Yahya SELAHVARZI', Navid VAHDATIMASHHADIAN' \\ ${ }^{1}$ Ferdowsi University of Mashhad, Agriculture Faculty, Horticultural Sciences Department, Mashhad, Iran; mortezaalirezaie@yahoo.com \\ ${ }^{2}$ Institute of Medicinal Plants, Department of Pharmacognosy and Pharmaceutics, ACECR, Tehran, Iran
}

\begin{abstract}
Colchicum kotschyi Boiss grows wildly in Iran. Propagation of this perennial geophyte plant takes a long time either by corm or seed. Seeds usually have a deep dormancy and take more than a year to germinate. Therefore in order to find out an effective method to shorten this period, a factorial experiment based on completely randomized design with four replicates was conducted to investigate the effects of warm stratification (no stratification and 8 weeks at $25^{\circ} \mathrm{C}$ ) and different chemical priming treatments. Priming was done by: $\mathrm{H}_{2} \mathrm{SO}_{4}(0$ and 50\%) and $\mathrm{GA}_{3}$ at $(0,250,500$ and $1000 \mathrm{ppm})$ and $\mathrm{KNO}_{3}$ at (1 and 2\%). Seeds were all cultured in a Potato Dextrose Agar media (1\%) and put in a dark position for germination. The results showed that warm stratification priming alone, had a germination percentage of 28.7\%. No germination was observed in control, $\mathrm{H}_{2} \mathrm{SO}_{4}$ and $\mathrm{KNO}_{3}$ treatments alone. Warm stratification along with GA significantly increased the germination percentage. Maximum germination percentage (70\%) was obtained in warm stratification and $\mathrm{GA}_{3}(1000$ $\mathrm{ppm}$ ). It seems that the germination problem for most of the Colchicum kotschyi seeds is probably due to a kind of morphophysiological dormancy which is broken by warm stratification along with $\mathrm{GA}_{3}$.
\end{abstract}

Keywords: Colchicum kotschyi, geophyte, morphophysiological dormancy, priming

\section{Introduction}

Colchicum genus belongs to the Colchicaceae family and is known as an important medicinal plant worldwide. The modern medicine uses Colchicum as a source of therapeutically active alkaloids called colchicinoids. One of the most abundant alkaloid-colchicine, is known to have cancerostatic, antirheumatic, antiinflammatory, antimitotic, cathartic and emetic effects (Boye and Brossi, 1992; Katzung, 2004).

In the previous studies, the existance of noticeable amounts of colchicine was observed in corms of Colchicum kotschyi (Alirezaie et al., 2010a) and phonological stage researches showed, that this plant is an autumn flowering geophyte from August to November in its native habitat (Noghondar hills around Mashhad -North east of Iran, 36 '22" latitude and 59'17' longitude) with hysteranthous leaves (Alirezaie et al., 2010b).

Propagation of this medicinal plant is done through seeds and corms. Propagation by corms is very slow as each corm produces one new corm (rarely tow) while the old one is shrunk. The germination of $C$. autumnale seeds is very poor and irregular (Ellington et al., 1997). Antonidaki-Giatromanolaki et al. (2008) reported irregular germination and low transplant survival of C. macrophyllom in its original habitat. They studied the effects of warm strati- fication, thermal and light treatments on germination of C. macrophyllom. Best results were recorded when seeds were pre-treated for 8 weeks at $20^{\circ} \mathrm{C}$ and removed to 15 or $10^{\circ} \mathrm{C}$ in darkness for germination. Cold stratification $\left(5^{\circ} \mathrm{C}\right)$ inhibited germination in all treatments. Light also decreased germination percentage compared to darkness (Antonidaki-Giatromanolaki et al., 2008).

Warm stratification was effective on germination enhancement of seeds with morphophysiological dormancy of the small, underdeveloped embryos such as Sambucus and Symphoricarpos (Hidayati et al., 2000; 2001). Acid scarification plus warm stratification plus cold stratification have been suggested as the best procedure to break dormancy in seeds (with intact stony endocarp) of Halesia (Young and Young, 1992), Rosa (Densmore and Zasada, 1997) and Rubus (Young and Young, 1992).

Different suggestions on how warm stratification can overcome dormancy are reported. Crocker and Barton (1957) suggested that soil microorganisms attacked the endocarps and broke them down while seeds were exposed to the warm, wet conditions during summer. Then, dormancy of the embryos was broken by cold stratification during winter, and seeds germinated in spring. While Baskin et al. (2002), from their study on E. hermaphroditum seeds suggested that warm stratification deals only with a part of embryo dormancy in seeds with intermediate physiologi- 
cal dormancy but not for morphological dormancy with stony endocarp.

According to Nikolaeva (1977), there are three types of physiological dormancy: nondeep, intermediate, and deep. Nondeep physiological dormancy is broken by relatively short (1-8 weeks) periods of warm or cold stratification, depending on the species, and gibberellic acid $\left(\mathrm{GA}_{3}\right)$ is effective in promoting germination (Baskin and Baskin, 1998). Intermediate physiological dormancy is broken by long (8-14 weeks) periods of cold stratification; however, dry storage (after-ripening) at room temperatures (Baskin and Baskin, 1998) or warm stratification (Baskin et al., 2002; Baskin and Baskin, 2004) may reduce the length of the cold stratification period needed to break dormancy. Also, GA can promote germination (Baskin and Baskin, 1998). Deep physiological dormancy is broken by long periods of cold stratification, and dry storage does not decrease the length of the cold stratification period required to break dormancy; $\mathrm{GA}_{3}$ is not effective in promoting germination (Baskin and Baskin, 1998).

$\mathrm{GA}_{3}$ is widely used to break dormancy of seeds of various plant species. Dormant seeds which require chilling, dry storage after ripening and light as a germination stimulator, are often treated with $\mathrm{GA}_{3}$ to overcome their dormancy (Gupta, 2003). Stratification along with chemical treatments has shown effectiveness for dormancy breaking as well. Applying $500 \mathrm{ppm}$ concentration of $\mathrm{GA}_{3}$ and 0.1 of $\mathrm{KNO}_{3}$ after stratification resulted in higher germination for water lily dormant seeds (Rouhil et al., 2010).

Antonidaki-Giatromanolaki et al. (2008) succeeded to overcome dormancy to less than one year and to accelerate germination by using warm stratification treatments and mentioned at the end that other pretreatment methods could be used for further experiments. Therefore, this experiment was conducted to find out a promising and practical method for breaking the dormancy and increasing germination percentage of Colchicum kotschyi Boiss for wide and commercial use with medicinal aims.

\section{Material and methods}

Mature seeds of Colchicum kotschyi were collected from a natural site from Noghondar hills around Mashhad -North east of Iran (36'22" latitude and 59'17' longitude), in June 2009. Seeds were then dried and kept in a dark room. In the next stage disinfection was done with sodium hypochlorite (5\%) for 5 minutes and washed with distilled water. After disinfecting, seeds were divided in two groups and treated with warm stratification (no stratification and 8 weeks, $25 \pm 5^{\circ} \mathrm{C}$ in moist peat) at first. After this stage, priming with $\mathrm{H}_{2} \mathrm{SO}_{4}$ was undertaken with no treatment and $\mathrm{H}_{2} \mathrm{SO}_{4}$ ( $50 \%$ for 30 minutes). Seeds were then soaked in $\mathrm{GA}_{3}$ at 3 levels (250, 500 and $1000 \mathrm{ppm}$ ) and $\mathrm{KNO}_{3}$ at 2 levels (1 and 2\%) and distilled water as control treatment. The experiment was conducted using 4 replicates and each replication contained 20 seeds. Afterwards seeds were located in Petri dishes and in PDA media (1\%) and placed in a germinator with $22^{\circ} \mathrm{C}$ and darkness to germinate. Statistical analysis was done using MSTAT - C software. Germination percentage data were converted to arcsine before variance analysis. The differences between the means were compared using Duncan test $(\mathrm{P} \leq 0.01)$.

\section{Results and discussion}

According to the results, warm stratification had a significant effect on germination of $C$. kotschyi seeds, as no germination was observed in treatments with any stratification. Germination percentage observed in seeds treated only with warm stratification was $28.7 \%$ (Tab. 1). Priming with $\mathrm{H}_{2} \mathrm{SO}_{4}(50 \%)$ showed no germination in either warm stratification treatments. In addition, application of $\mathrm{KNO}_{3}$ alone and in combination with other treatments did not affect seed germination and showed no germination (Tab. 1). GA alone also had no germination effect, but when interacted with warm stratification, it increased germination percentage and this increase was related to $\mathrm{GA}_{3}$ concentration, positively. Maximum germination percentage, (70\%), was obtained in warm stratification priming and $\mathrm{GA}_{3}$ (1000 ppm) (Tab. 1). Germination was stopped by day 65 from the start of the experiment in all treatments used. Data collection was continued to after 4 months after seed culture in PDA, but no germination or significant change was observed within the treatments in this period (after 65 days).GA in seeds treated with warm stratification, is not needed for germination, but the presence of this phytohormone can increase final germination percentage, significantly. The results agree with Antonida-

Tab. 1. Final germination percentage of C. kotschyi seeds treated with and without warm stratification and chemical treatments $\left(\mathrm{H}_{2} \mathrm{SO}_{4}, \mathrm{GA}_{3}\right.$ and $\left.\mathrm{KNO}_{3}\right)$

\begin{tabular}{cccccc}
\hline \multirow{2}{*}{ Treatments } & \multicolumn{2}{c}{+ Warm stratification } & \multicolumn{2}{c}{-Warm stratification } \\
\cline { 2 - 6 } & 0 (distillate water) & $+\mathrm{H}_{2} \mathrm{SO}_{4}(50 \%)$ & $-\mathrm{H}_{2} \mathrm{SO}_{4}$ & $+_{2} \mathrm{HO}_{4}(50 \%)$ & $-\mathrm{H}_{2} \mathrm{SO}_{4}$ \\
\hline \multirow{2}{*}{$\mathrm{GA}_{3}(\mathrm{ppm})$} & 250 & $0 \mathrm{e}$ & $28.7 \mathrm{~d}$ & $0 \mathrm{e}$ & $0 \mathrm{e}$ \\
& 500 & $0 \mathrm{e}$ & $55 \mathrm{c}$ & $0 \mathrm{e}$ & $0 \mathrm{e}$ \\
& 1000 & $0 \mathrm{e}$ & $62.5 \mathrm{~b}$ & $0 \mathrm{e}$ & $0 \mathrm{e}$ \\
$\mathrm{KNO}_{3}(\%)$ & 1 & $0 \mathrm{e}$ & $70 \mathrm{a}$ & $0 \mathrm{e}$ & $0 \mathrm{e}$ \\
& 2 & $0 \mathrm{e}$ & $0 \mathrm{e}$ & $0 \mathrm{e}$ & $0 \mathrm{e}$ \\
\hline
\end{tabular}

Note: Different letters between data denote significant differences (Duncan test, $\mathrm{p}<0.01$ ) 
106

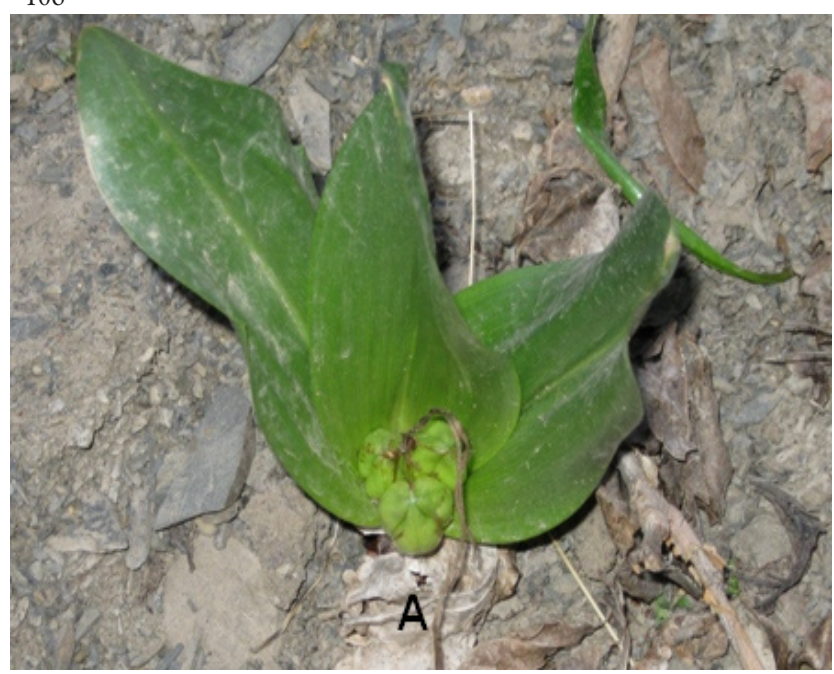

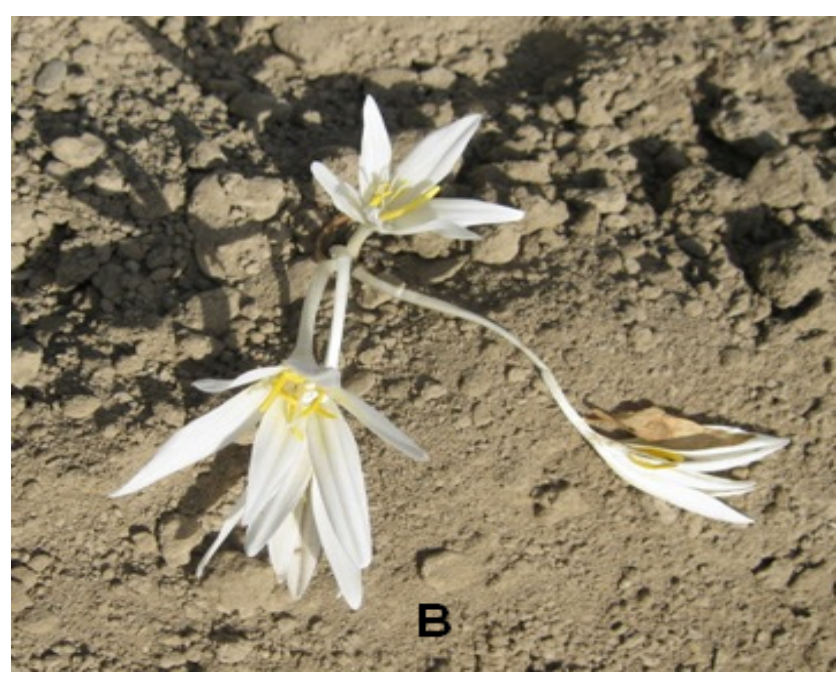

Fig.1. Colchicum kotschyi Boiss, vegetative growth (A) and flowering stage (B)

ki-Giatromanolaki et al. (2008), on benefits of warm stratification on Colchicum variety seeds. $\mathrm{GA}_{3}(1000 \mathrm{ppm})$ combined with warm stratification had a significant effect on germination percentage compared to warm stratification only and increased this index form 28.7 to $70 \%$.

Whether a seed is dormant or non-dormant may vary within species and individuals. Thus, a portion of a seed collection may contain seeds that are dormant, as well as those that are non-dormant or conditionally dormant (Baskin and Baskin, 2004). Results indicate that warm stratification is necessary for dormancy breaking and germination, but it is not enough for reaching maximum germination. It seems that the problem to seed germination of Colchicum kotschyi (Fig. 1) is probably not only due to an immature embryo and a kind of morphophysiological dormancy (MPD); this concludes that $\mathrm{GA}_{3}$ should be used along with warm stratification in order to overcome the seed dormancy and start germination.

Seeds with MPD have an underdeveloped embryo with a physiological component of dormancy. There are eight known levels of MPD, based on the protocol for seed dormancy break and germination. In seeds with non-deep simple MPD, warm or cold stratification break dormancy and $\mathrm{GA}_{3}$ overcome dormancy (Baskin and Baskin, 1998; Walck et al., 1999).

According to the results, it seems that $28.7 \%$ of $C$. kotschyi seeds have morphological dormancy (underdeveloped embryo) which is broken under warm stratification ( 8 weeks) and $41.3 \%$ of the seeds have non-deep simple MPD which has to be broken with $\mathrm{GA}_{3}(1000 \mathrm{ppm})$ along with warm stratification.

\section{Conclusions}

In conclusion, according to the results of this experiment, warm stratification $\left(8\right.$ weeks, $\left.25^{\circ} \mathrm{C}\right)$ in addition with $\mathrm{GA}_{3}$ overcomes the dormancy and significantly increases germination percentage of Colchicum kotschyi; under such conditions germination takes place in less than 6 months according to the experiment

\section{References}

Alirezaie Noghondar M, Arouiee H, Rezazadeh Sh, Shoor M (2010a). Determination of colchicine content in two Colchicum species (Colchicum kotschyi and C. robustum). In: Scientific conference on medicinal plants industry development in Iran, Tehran.

Alirezaie Noghondar M, Arouiee H, Rezazadeh Sh, Shoor M (2010b). Study on different phonological stages of tow medicine Colchicum species (Colchicum kotschyi and C. robustum). In: Scientific conference on medicinal plants industry development in Iran, Tehran.

Antonidaki-Giatromanolaki A, Dragassaki M, Papadimitriou M, Vlahos I (2008). Effects of stratification, temperature and light on seed germination of Colchicum macrophyllum $\mathrm{b}$. L. Burtt. Propagation of Ornamental Plants 8(2):105-107.

Baskin CC, Baskin JM, Meyer SE (1993). Seed dormancy in the Colorado Plateau shrub Mahonia fremontii (Berberidaceae) and its ecological and evolutionary implications. Southwestern Naturalist 38:91-99.

Baskin CC, Baskin JM (1998). Seeds, Ecology, biogeography, and evolution of dormancy and germination. San Diego, Academic Press, New York.

Baskin CC, Baskin JM (2004). A classification system for seed dormancy. Seed Science Research 14:1-16.

Baskin CC, Zackrisson O, Baskin JM (2002). Role of warm stratification in promoting germination of seeds of empetrum hermaphroditum (empetraceae), a circumboreal species with a stony endocarp. American Journal of Botany 89(3):486493.

Boye O, Brossi A (1992). Tropolonic Colchicum alkaloids and allo congeners, p. 125-174. In: Brossi A and Cordell GA (Eds.). The Alkaloids. Academic Press, New York.

Crocker W, Barton LV (1957). Physiology of seeds. Chronica 
Botanica, Waltham, Massachusetts.

Densmore R, Zasada JC (1977). Germination requirements of Alaskan Rosa acicularis. Canadian Field-Naturalist 91:5862.

Ellington E, Adserias T, Coma A, Bastida F, Viladomat F and Codina C (1997). Effect of paclobutrazol on in vitro culture of Colchicum autumnale corms. Acta Hortic 447:131-134.

Gupta V (2003). Seed germination and dormancy breaking techniques for indigenous medicinal and aromatic plants. J Med Arom Plant Sci 25:402-407.

HidayatiSN,BaskinJM,BaskinCC(2000).Morphophysiological dormancy in seeds of two North American and one Eurasian species of Sambucus (Caprifoliaceae) with underdeveloped spatulate embryos. American Journal of Botany 87:16691678.

HidayatiSN, Baskin JM, Baskin CC (2001). Dormancy-breaking and germination requirements for seeds of Symphoricarpos orbiculatus (Caprifoliaceae). American Journal of Botany 88:1444-1451.
Katzung GB (2004). Basic and Clinical Pharmacology, $9^{\text {th }}$ Ed. The McGraw- Hill companies Inc USA 133:627-631.

Nikolaeva MG (1977). Factors controlling the seed dormancy pattern, p. 51-74. In: Khan AA (Eds.). The physiology and biochemistry of seed dormancyand germination. NorthHolland, Amsterdam, The Netherlands.

Rouhi HR, Shakarami K, Tavakkol Afshari R (2010). Seed treatments to overcome dormancy of waterlily tulip (Tulipa kaufmanniana Regel.). Australian Journal of Crop Science 4(9):718-721.

Walck JL, Baskin CC, Baskin JM (1999). Seeds of Thalictrum mirabile (Ranunculaceae) require cold stratification for loss of nondeep simple morphophysiological dormancy. Canadian Journal of Botany 77:1769-1776.

Young JA, Young CG (1992). Seeds of woody plants in North America. Dioscorides Press, Portland, Oregon, USA. 